University of Texas at Tyler Scholar Works at UT Tyler

$5-12-2015$

\title{
A personal journey to merge literacy education and multicultural teacher education
}

Gina M. Doepker

University of Texas at Tyler, gdoepker@uttyler.edu

Follow this and additional works at: https://scholarworks.uttyler.edu/education_fac

Part of the Education Commons

\section{Recommended Citation}

Doepker, Gina M., "A personal journey to merge literacy education and multicultural teacher education" (2015). Education Faculty Publications and Presentations. Paper 15.

http://hdl.handle.net/10950/602 
Gina M. Doepker*

\title{
A Personal Journey to Merge Literacy Education and Multicultural Teacher Education
}

\begin{abstract}
There has been considerable attention to multicultural education and how to effectively integrate it into teacher education programs so that it helps teachers to be attentive to and effective for the economically, culturally, and racially diverse student populace. This article will focus on my personal journey with multicultural teacher education and literacy education. There will be a discussion of multicultural or diverse-oriented teacher education with a focus on the challenges as well as the potentials that face these teacher preparation programs. In addition, there will be a discussion of current educational trends in schools as evidence that demands the need for stronger multicultural teacher education programs. Finally, an existing teacher education program will be presented that has an emphasis on multicultural teacher training, as well as suggest approaches for building a research-based multicultural teacher education program.
\end{abstract}

Keywords: literacy education, multicultural education, teacher education

DOI 10.1515/mlt-2015-0003

Imagine a seventh-grade urban classroom with a majority of students that were African American. The lead teacher in this classroom was a White woman who was mentoring a young White female preservice teacher candidate. Early in the practicum experience, the preservice teacher revealed to her university supervisor that she was overwhelmed, scared, and felt extremely unprepared for this particular field placement. The university supervisor, also being a White woman, immediately gave this preservice teacher a pep talk in order to increase her selfconfidence as well as suggested some classroom strategies that worked during her own past teaching career. The university supervisor also advised this preservice teacher to discuss her questions and concerns with her mentor teacher. What the university supervisor did not reveal was that her own past teaching

*Corresponding author: Gina M. Doepker, Early Childhood and Special Education, Valdosta State University, 1500 N. Patterson St., Valdosta, GA 31698-0092, USA, E-mail: gmdoepker@valdosta.edu 
career involved teaching predominantly White students. This preservice teacher finished her field experience and stated that she would never return to this particular school again. I was the university supervisor who advised, or illadvised, this preservice teacher candidate.

\section{Insufficient exposure and isolated experiences}

As a university supervisor of preservice teacher candidates, I must observe and support preservice teacher candidates in their practicum classrooms during their clinical field experiences. I have supervised preservice teachers in many private and public school classrooms ranging from kindergarten through eighth grade. These classrooms were set in both suburban and urban schools. Fortunately, a White male preservice teacher unknowingly forced me to reflect on and reevaluate my own education and training as a teacher. His honest evaluation of my supervisory performance revealed that my advice and support was not relevant for his particular needs. His clinical field placement was in an urban school setting with a very high population of African American students. After receiving this preservice teacher's valuable evaluation, my immediate question became, "How can a White woman give advice and support to preservice teacher candidates regarding their African American students?" According to Obi, Obiakor, Gala, and Magee (2013), "Multicultural education is a progressive approach for transforming education that holistically critiques and addresses current shortcomings, failings, and discriminatory practices in schools, and in doing so, works toward change in the larger society” (p. 159). I seriously had to reflect on my failings as a university supervisor, my shortcomings, as well as my discriminatory practices in order to answer this essential question listed above. I needed to examine and reflect on my past experiences as a student, an elementary teacher, and a university supervisor. I was a relatively young, middleclass, White woman who had always resided in suburban areas.

As a student, I went to a private, Catholic school from kindergarten through my master's degree. This education led me to a career as an elementary school teacher where I was employed at a private, Catholic elementary school in an urban community for six years. I eventually re-enrolled back in school, but this time I attended a public university for my doctoral studies. All of my educational experiences before my doctoral studies involved classrooms filled with White students, one of which included me. There was an occasional African American student in these classrooms, but this was an infrequent occurrence. During my doctoral program I became a university supervisor of preservice teacher 
candidates. For the first time in my life, I experienced classrooms that were filled with African American students. I was definitely not adequately prepared for my new role as a university supervisor and clearly lacked the knowledge and experiences needed regarding multicultural teacher education and/or culturally relevant teaching (Ladson-Billings, 1994). At that moment in my life, I was an advanced doctoral student, but I was also completely ignorant at the same time.

Unfortunately, my educational experiences as a very sheltered and naïve student mirrors the educational experiences of many other students in the United States. In reflecting on the teacher education program that I completed as an undergraduate and master's student, I realized that before my doctoral studies I lacked any relevant or meaningful training in how to teach students who were not White. I held the mistaken belief that all students should be treated and taught the same way. I was "color blind". The well-intentioned, but misguided advice that I gave that female preservice teacher candidate was effective for me, but my students were all White and hers were not. The concept of multicultural teacher education was introduced to me when I began my doctoral studies at the public university. I now am a strong supporter of multicultural teacher education and diversity training to expand from preschool through college. My own study in multicultural teacher education had only just begun during my doctoral studies. I am continually developing in my knowledge of multicultural teacher education, and have progressed as an antiracist human being. Prior to my doctoral studies, I did not acknowledge that I was a racist, but quickly realized that White supremacy involuntary ruled my behaviors, beliefs, and entire life to that point. This realization was unsettling and redeeming at the same time - unsettling because I was now knowingly questioning everything that I knew to be true; and redeeming because now my thinking and my life would and could never be the same again. The veil had been lifted and I could finally see. Today, I do not want any preservice teacher candidate to emerge into today's educational system with the same "color blindness" that I had. I want them to embrace multicultural teacher education and have a firm grasp on how to teach the diverse student body of today.

\section{Merging literacy education and multicultural teacher education}

Fortunately, I am in a position where I can truly help and support preservice teacher candidates to become effective teachers for all children. My current experiences with racial diversity and multiculturalism are vastly different from 
my earlier, more sheltered and naïve years. I am an associate professor in the department of Early Childhood and Special Education at a comprehensive university in South Georgia. I teach undergraduate junior and senior level literacy education courses. I teach my students (about 56 students to be exact) how to teach their future students how to read and write. These literacy education methods courses incorporate one-on-one literacy tutoring with children from the community and local schools. Being in South Georgia, the racial composition of my current students ranges from $63 \%$ being White and 37\% being African American, while the racial composition of the community children being tutored ranges from 30\% being White and 70\% being African American. As a result of the racial discrepancy between my students and the community children they tutor, my students need to be culturally responsive, as well as effective literacy instructors in order to meet the individual needs of these community children. I am obligated to ensure that my students are ready for this awesome responsibility. I cannot repeat the same misinformed and misguided mistakes of my past.

\section{Imperative educational changes}

Teacher education programs throughout the United States have experienced a pedagogical shift. This shift was required due to the increasing numbers of diverse students who are entering American classrooms. The face of American classrooms has changed significantly starting from the civil rights movement of the 1950s and 1960s. The increase of students of diverse races and cultures has necessitated the need for teacher educators to reevaluate and reform their curricular programs to include multicultural and diversity training for their preservice teacher candidates. My own literacy methods courses were not immune from these curricular changes. This change has been transformational to the field of teacher education, but this change is constantly being reevaluated and reshaped as teacher educators discover more effective methods to preparing preservice teachers to teach in the culturally pluralistic society of today. Cultural pluralism is vital to multicultural education. The Commission on Multicultural Education (1973) stated that:

Cultural pluralism is more than a temporary accommodation to placate racial and ethnic minorities. It is a concept that aims toward a heightened sense of being and of wholeness of the entire society based on the unique strengths of each of its parts....The commitment to cultural pluralism must permeate all areas of the educational experience provided for prospective teachers. (p. 264) 
This position is an all-inclusive societal construction based on cultural differences that unify and strengthen society as a whole. Multicultural teacher education must adopt cultural pluralism as an equity pedagogy for preservice teacher candidates. Banks and Banks (1995) described equity pedagogy as, "teaching strategies and classroom environments that help students from diverse racial, ethnic, and cultural groups attain the knowledge, skills, and attitudes needed to function effectively within, and help create and perpetuate, a just, humane, and democratic society" (p. 152). Equity pedagogy must be addressed and embraced throughout university teacher education programs, which will ultimately be a part of classrooms all around the United States. I had to adopt this equity pedagogy within my own college classrooms in order for my students, and preservice teacher candidates, to also adopt this equity pedagogy in their own teaching.

There have been a multitude of documented approaches to multicultural teacher education. Sleeter and Grant (1987) emphasized five different approaches that have been integrated into teacher education programs. The first approach, that they labeled "Teaching the Culturally Different," integrates ethnically diverse students by providing transitions into the existing school program. The absurdity in this approach is that the ethnically diverse student must change to fit the dominant social order of schools, rather than implementing different methodologies that support their individual learning needs. The second approach, "Human Relations," encourages all students to appreciate the differences that each student brings to the classroom in an attempt to mollify any conflict that may accrue. In the "Human Relations" approach, the emphasis is on social order rather than education. The third approach labeled "Single Group Studies," is also flawed. According to Sleeter and Grant, this approach "fosters cultural pluralism by teaching courses about the experiences, contributions, and concerns of distinct ethnic, gender, and social class groups" (p. 422). This approach limits the exposure to all different cultural groups by focusing instruction on single cultural groups. It also creates isolated courses that focus on multiculturalism rather than integrating multiculturalism into all course content. The fourth approach, "Multicultural Education," includes a curriculum focused on cultural pluralism as well as equity pedagogy and reflects diversity throughout its program. This approach is an all-inclusive balanced curriculum with instructional materials that support the diverse student population by recognizing both cultural and language diversity. The final approach, "Education That Is Multicultural and Social Reconstructionist," takes multicultural education to the next level. This approach stresses the need for social change by challenging inequalities and promoting cultural diversity. 
Another way to look at multicultural teacher education is through the educational program reform lens to see how it is being offered. Lien (1999) described two types of approaches that colleges and universities have implemented in order to prepare teachers for multicultural education. One approach is an additive approach by offering separate courses that introduce multicultural education, such as in the "Single Group Studies" mentioned by Sleeter and Grant (1987). As a result, some colleges or universities may only offer one course in order to fulfill this requirement. This approach is ineffective because it does not integrate multiculturalism into all of the courses taken by the preservice teacher candidates. This additive approach is also very limiting in that it suggests that multiculturalism is a separate entity that does not affect all aspects of education and/or society. Gomez (1996) likewise argues that the additive approach to multicultural education "only begins to challenge prospective teachers' beliefs about diverse people; they seldom address the knowledge, skills, and dispositions required to increase diverse children's learning and achievement" (p. 118). In opposition to the additive approach is an infusion approach which integrates all aspects of multiculturalism throughout the entire teacher education curriculum. Through the infusion approach, preservice teacher candidates learn the knowledge and skills necessary for teaching in the culturally diverse society. Infusion of multiculturalism throughout the curriculum should be a priority spearheading multicultural teacher education reform.

A final way to view multicultural teacher education is through the paradigm lens. Shade (1995) argued that, "implementing a multicultural focus in a teacher preparation program in a predominantly White school requires a paradigmatic shift; it provides a social, intellectual, and emotional challenge for everyone involved" (p. 375). Preservice teachers, students, and society must make a paradigm shift from traditional views of teacher education to include multicultural education. Banks (1991) revealed several paradigms that tied directly to multicultural education, but the first two paradigms support social inequality which is ultimately detrimental to the education of ethnically diverse students. The cultural deprivation paradigm stresses that ethnically diverse as well as economically lower class students are also academically lower achievers due to their pathological nature of their culture. The genetic paradigm likewise charges that academic difficulty and failure is a result of inferior genetic characteristics. These two paradigms sanction teachers' beliefs that ethnically diverse students' academic difficulties are created by environmental and biological causes that are beyond their control. According to Banks (1991), "Using either of these paradigms, educators can 'blame the victims' for their academic failures" (p. 139), thereby taking the educational responsibility out of their hands. An alternative paradigm incorporates Gardner's theory of multiple intelligences 
where students, no matter their background, possess different ways of learning. Unfortunately, Banks (1991) declared that, "many educational practitioners either reject or are unaware of these newer paradigms and continue to hold traditional and highly restricted notions of human intelligence" (p. 139). Through proper multicultural education, preservice teacher candidates can learn how to accommodate and support these multiple intelligences in order to maximize learning of all students, but just providing the proper multicultural education does not automatically mean that preservice teacher candidates are willing or able to learn these effective educational methods.

As a university professor, I am proud to say that our courses in the Department of Early Childhood and Special Education have undergone a transformation model of reform in order to integrate the infusion model and guarantee that each course has a focus on diversity or multicultural education in some way, as well as embrace the multiple intelligences paradigm. My literacy education methods courses emphasis diversity and differentiated instruction based on the child's individual needs. Within my literacy courses, my students are taught how to assess children's individual reading and writing skills, as well as how to implement individualized literacy instruction that is meaningful, relevant, and purposeful. According to Obiakor and Algozzine (as cited in Obiakor, 2014), "While some knowledge of multicultural education has been a good thing: it has become increasingly evident that having the knowledge is not enough anymore - knowledge must be followed by measurable commitment and action" (p. 183). My students do take action by applying this new knowledge directly in their one-on-one tutoring sessions with racially diverse community children. Their primary goal is to build up these children's reading and writing motivation, confidence, and skills based on their particular child's individual learning needs.

\section{Challenges and potentials of multicultural teacher education}

Multicultural teacher education has experienced a pedagogical transformation which is not void of some relevant challenges. While teacher education programs have changed, the preservice teacher candidate population has not changed. Data regarding the demographics of the current teaching force shows an educational system dominated by young, White, and middleclass females, whereas the demographics of the student population continues to steadily increase in diversity. There is a serious racial mismatch between the current teacher population and student population which poses unavoidable challenges 
for multicultural teacher education programs. This racial mismatch is a reality for my students as well. As stated earlier, 63\% of my students are White while $70 \%$ of the community children that they tutor are African American.

One major challenge for these preservice teachers is conquering their biases and beliefs regarding the ethnically diverse student population. Seidl and Friend (2002) noted that, "an equal-status partnership is better positioned to de-center this privileged cultural stance and help [preservice teachers] begin to question their own hegemonic cultural beliefs and the racist social ideologies that sustain them" (p. 425). Living in a White dominated society makes it hard to dismiss monocultural opinions and beliefs that embody all aspects of society including education. According to Banks (1991), “Teachers are human beings who bring their cultural perspectives, values, hopes, and dreams to the classroom. They also bring their prejudices, stereotypes, and misconceptions" (p. 139). College students entering teacher education not only bring their own naïve understanding of cultural diversity, but they also have pre-existing attitudes, beliefs, and stereotypes which have been influenced by a monocultural White dominated society. Unfortunately, despite the multicultural reform efforts some preservice teacher candidates resist changing their prejudiced attitudes about the African American culture. Seidl and Friend (2002) stated that this resistance "reminded [them] of the resiliency of long-held social and cultural beliefs as some students demonstrate little growth, remaining within a fixed dominant paradigm and displaying many of the ideological defenses White students utilize to resist personal and social transformation" (p. 427). Unfortunately, some of my students also resist the paradigm shift to support multiculturalism and remain "color-blind" to the African American experiences by treating these diverse students as if they are White. As to Tran, Young, and Di Lella (1994) pointed out, "critics attack multicultural training as having minimal positive effects of multicultural training on stereotypical attitudes towards ethnic groups” (p. 184). Some preservice teacher candidates may either retain these potentially negative attitudes and beliefs by consciously rejecting multicultural education, or unconsciously through dysconscious racism. Baker and McDermott (2000) observed that, "White teachers are often, consciously or unconsciously, insensitive and biased against children's life experiences which they have not seen or do not understand" (p. 3). Lien (1999) likewise affirmed that conscious resistance or the “oppositional notion of 'self versus the others' is a mechanism of maintaining White supremacy and cultural hegemony” (p. 4). Conversely, the unintentional resistance to multicultural education implicates dysconscious racism. King (1991) defined dysconsciousness as, "an uncritical habit of mind (including perceptions, attitudes, assumptions, and beliefs) that justifies inequity and exploitation by accepting the existing order of things as given” (p. 135). 
Dysconscious racists silently accept the dominant White supremacist position. Grouix (2001) argued that dysconscious racism may be attributed to a "chronic lack of self-awareness about one's own assumptions” (p. 62), which solidifies their acceptance of White dominance. Preservice teacher candidates' prejudicial and biased way of thinking and believing creates a major challenge to multicultural teacher education programs.

If multiculturalism and diversity training is infused throughout the entire teacher education curriculum then there is great potential to help preservice teacher candidates to acquire the necessary skills, knowledge, and dispositions required for teaching the ethnically diverse student population of today. Obiakor (2014) stated:

....when infused properly, multicultural education has the power to change attitudes and enhance quality education, especially when it (a) exposes individuals to maximum learning and new dimensions of problem-solving; (b) acquaints individuals with divergent viewpoints and multiple voices to societal discourse; (c) removes limits set on how people are defined, understood, and valued; and (d) increases how people collaborate, consult, and cooperate with each other. (p. 185)

Teacher educators, as well as preservice teacher candidates, need to reflect on and acknowledge their own cultural origins, beliefs, and values before they can begin to understand and appreciate the strengths and capabilities that ethnically diverse students bring to the classroom. I personally experienced this life changing transformation, and need to support my students to go through the transformational process to embrace multiculturalism and diversity. Delpit (1995) urged the entire educational system to commit to infusing multicultural education throughout the curriculum and defeat prior misunderstandings regarding racial diversity. She wrote:

When we teach across the boundaries of race, class, or gender - indeed when we teach at all - we must recognize and overcome the power differential, the stereotypes, and the other barriers which prevent us from seeing each other. Those efforts must drive our teacher education, our curriculum development, our instructional strategies, and every aspect of the educational enterprise. Until we can see the world as others see it, all the educational reforms in the world will come to naught. (p. 134)

Multicultural educational reform must be infused throughout the entire curriculum. This significant reform effort requires that administrators, faculty, and preservice teacher candidates are actively implementing multicultural teaching and learning experiences throughout the curriculum in order for racially diverse students to become productive members of society. Effective multicultural teacher education has the potential to help preservice teacher candidates to become 
active agents for social change. Reed (1993) suggested that an effective multicultural teacher education program must mandate the following explicit goals:

Prospective teachers must be taught to understand and appreciate the many cultures that exist in our society. They must be taught to value cultural diversity. They must be taught that through their expectations, actions, words, and deeds as classroom teachers, they can foster acceptance and respect of all children. They must be taught that they have a legal, ethical, and moral responsibility to provide the best education they possibly can to members of all racial, ethnic, and cultural groups. (p. 28)

\section{Building a powerful multicultural teacher education program}

It is easy to charge colleges and universities with the task of infusing multicultural education throughout their teacher preparation programs, but it is difficult to communicate how to provide effective multicultural education. Initially, some colleges and universities responded to this charge by adding one course called "Multicultural Education". Regrettably, this one course may have actually strengthened preservice teachers' preconceived prejudices and biases about diversity and other cultures. As stated earlier, Sleeter and Grant's (1987) "Single Group Study" is an ineffective approach to multicultural education. Fortunately, multicultural teacher education continues to change as institutions are trying different approaches, changing ineffective approaches, and ultimately reforming their programs in order to provide an effective multicultural education for their preservice teacher candidates. Ultimately these reform efforts are complex and challenging. Seidl and Friend (2002) stated:

Teacher education continues to struggle to find experiences sufficiently powerful to support students in deconstructing the messy tangle of racism, classism, poverty, sexism, and opportunity and is much less successful in helping students reconstruct maintainable positions within a commitment to social justice. (p. 422)

This complex challenge to implement effective methods for preparing preservice teachers to enter today's ethnically and culturally diverse classrooms has led to innovative approaches that are changing the face of teacher education forever. This multicultural reform has been a struggle, but the struggle has brought needed change and action. This reform has given voices to African American student, Hispanic American student, Asian American student, Native American student, and all other non-white students. Teacher education is responding to the diverse needs of these students. 
Multicultural teacher education must have a central goal of building a strong knowledge base regarding multiculturalism. This goal can be partially met through infusion of multiculturalism throughout the curriculum where courses are purposely designed to integrate multicultural themes within the content of the courses. Torok and Aguilar (2000) proposed that multicultural education should integrate the following core concepts: "culture, ethnicity, race/racism, class/classism, gender and sexual orientation, religious diversity, language diversity, and disability/special education" (p. 25). These core concepts can be imbued throughout the course content through methods such as textbook assignments, written reflections, discussions, seminars, exams, and thematic units. Through this university course work, preservice teacher candidates can begin to build a knowledge base and theoretical understanding regarding the core concepts of multiculturalism. However, university course work alone only partially fulfills the goal of full concept attainment. To attain this full concept knowledge, the course work must occur in conjunction with meaningful, relevant, and purposeful field experiences so that preservice teacher candidates can apply theory to practice and learn by doing. My students are definitely experiencing the realities of racial diversity and are learning by doing!

Multicultural teacher education courses must include some type of writing exercise. Stimulating cognitive processes is essential for learning and writing can serve as this cognitive stimulant. There are a variety of writing formats that can stimulate critical thinking which can lead to a deeper level of learning. These writing formats include: research papers, reaction papers, personal theory papers, position papers, autobiographies, and/or journaling. Research papers force preservice teacher candidates to choose and investigate a current issue or trend related to multiculturalism and racial diversity. Choice of topic is a powerful method to foster personal interest and investment in finding answers to their questions. Reaction papers can likewise be completed throughout their multicultural training. Preservice teacher candidates can initially analyze their thoughts, beliefs, and values related to their existing cultural understandings. They can revisit and re-analyze these perspectives throughout their multicultural training. These reaction papers are eventually compared by the preservice teacher candidates to identify their personal growth and possible change in perspectives and understandings. Ross and Smith (1992) explained that personal theory papers are the, "students' [descriptions] of their beliefs about the purposes of schooling, the nature of the process of teaching and learning, and the two or three strongest influences on their beliefs about teaching and learning" (p. 94). Position papers push preservice teacher candidates to choose a stance and argue for or against specific multicultural issues. Autobiographies permit 
preservice teacher candidates to critically analyze their personal beliefs about their own cultural backgrounds before they can learn about and appreciate other cultural backgrounds. Preservice teacher candidates can hash out their thoughts, feelings, and attitudes regarding their experiences with multicultural training through a dialogue journal. These different writing exercises can help preservice teacher candidates to build a deeper understanding of multiculturalism and diversity. My students are required to complete written reflective commentaries after each lesson that they implement with the child that they are tutoring. These lesson reflections include prompts that allow them to consider their overall effectiveness, concerns, questions, and confusions. Their commentaries can focus on a variety of topics including literacy skills instruction, behavior management, and cultural responsivity. Through these reflective commentaries, I have the chance to provide appropriate and relevant feedback for their particular needs, which is unlike the advice that I gave my preservice teacher candidates many years ago.

Educational seminars can be also an effective method in building multicultural awareness. Seminars can focus on relevant issues and trends related to multiculturalism and diversity. Students would be encouraged and prompted to become active participants in seminar discussions. According to Bowen and Salsman (1979), the goal of the seminar is:

(1) expand the participants' knowledge of their own and other cultures; (2) to deepen and to increase the participants' awareness of their own cultural identity; (3) to help participants develop a better understanding of various ways to expand their contacts with other cultural groups, and to become better acquainted with their own cultural roles; and, (4) to develop the participants' capacities for humane, sensitive and critical inquiry into the nature of cultural issues, particularly as these may relate to education. (p. 391)

In Mills (1984) Multicultural Teacher Education Program, he facilitated collaborative and cooperative teaching seminars between his White preservice teacher candidates and African American preservice teacher candidates from a neighboring educational institution. These collaborative seminars helped all of the preservice teacher candidates to learn about each other and gain a deeper understanding regarding their diversity. I do not currently facilitate these educational seminars to discuss and address pertinent topics with my students, but I do allow time at the start of each class session to discuss their questions, concerns, and confusions related to their one-on-one tutoring experiences. This informal sharing time is extremely valued by my students. The informal sharing allows them to discuss their tutoring questions and concerns, listen to their peers, share ideas, and problem-solve solutions. 


\section{Conclusion}

It has been a tremendous journey for me to become multiculturally aware and responsive. The guidance, advice, and instruction that I give my preservice teacher candidates is no longer irrelevant and inappropriate. All students should be held to high expectations and need instruction that is relevant, meaningful, and purposeful based on their individual needs. It is importance of increase each student's motivation, confidence, and skills to help them to be independent learners. My challenge is to help and support my preservice teacher candidates to become multiculturally aware and responsive as well. The urgency for culturally responsive teaching is essential given the mounting diversity in schools today. There are definite challenges to creating and implementing an effective multicultural teacher education program, but there are also potential methods for preparing preservice teacher candidates to teach in culturally diverse classrooms. These methods consist of a multicultural infusion within the entire teacher education curriculum, multicultural course assignments, indepth self-analysis, engaging and relevant field experiences, and critical reflection that is dialogic. Preservice teacher candidates need to embrace equity pedagogy and culturally responsive teaching as a means to help all students to succeed in their educational development. This is not an option.

\section{References}

Baker, K., \& McDermott, P. (2000, April). Provocative and powerful children's literature: Developing teacher knowledge and acceptance of ethnic and cultural diversity. Paper presented at the annual meeting of the American Educational Research Association, New Orleans, LA.

Banks, J. A. (1991). Teaching multicultural literacy to teachers. Teaching Education, 4(1), 135-144.

Banks, C. A. M., \& Banks, J. A. (1995). Equity pedagogy: An essential component of multicultural education. Theory Into Practice, 34(3), 152-158.

Bowen, E. M., \& Salsman, F. L. (1979). Integrating multiculturalism into a teacher-training program. Journal of Negro Education, 48(3), 390-395.

Commission on Multicultural Education. (1973). No one model American. Journal of Teacher Education, 24(4), 264-265.

Delpit, L. (1995). Other people's children: Cultural conflict in the classroom. New York, NY: The New Press.

Doepker, G. M. (2014). Multicultural teacher education and literacy education: One teacher educators journey from ignorance to insight. In F. E. Obiakor, J. Bakken, \& B. Algozzine (Eds.), White voices in multicultural psychology, education, and leadership: Inside the walls of American's higher education (pp. 149-166). New York, NY: Nova Publishers. 
Gomez, M. L. (1996). Prospective teachers' perspectives on teaching "other people's Children.” In K. Zeichner, S. Melnick, \& M. L. Gomez (Eds.), Currents of reform in preservice teacher education (pp. 109-131). New York, NY: Teachers College Press.

Grouix, J. G. (2001). Changing preservice teacher perceptions of minority schools. Urban Education, 36(1), 60-92.

King, J. E. (1991). Dysconscious racism: Ideology, identity, and the miseducation of teachers. Journal of Negro Education, 60(2), 133-146.

Ladson-Billings, G. (1994). The dreamkeepers: Successful teachers of African American Children. San Francisco, CA: Jossey-Bass.

Lien, H. N. (1999, April). A challenge toward binary racial epistemology: The reconstruction of cultural identity in multicultural teacher education. Paper presented at the annual meeting of the American Educational Research Association, Quebec, Canada.

Mills, J. R. (1984). Addressing the separate-but-equal predicament in teacher preparation: A case study. Journal of Teacher Education, 35, 18-23.

Obi, S. O., Obiakor, F. E., Gala, D. D., \& Magee, S. (2013). Diversity, technology, and global interactions: Educational implications. In S. Abebe (Ed.), Diversity in education: An integrated framework beyond chalk and talk (pp. 157-181). Ronkonkoma, NY: Linus Learning.

Obiakor, F. E. (2014). Multicultural Education: The mismeasured but important phenomenon. In A. J. Holliman (Ed.), The Routledge international companion to educational psychology (pp. 181-190). New York, NY: Routledge.

Reed, D. F. (1993). Multicultural education for preservice students. Action in Teacher Education, 15(3), 27-34.

Ross, D. D., \& Smith, W. (1992). Understanding preservice teachers' perspectives on diversity. Journal of Teacher Education, 43(2), 94-103.

Seidl, B., \& Friend, G. (2002). Leaving authority at the door: Equal-status community-based experiences and the preparation of teachers for diverse classroom. Teaching and Teacher Education, 18, 421-433.

Shade, B. (1995). Developing a multicultural focus in teacher education: One department's story. Journal of Teacher Education, 46(5), 375-380.

Sleeter, C. E., \& Grant, C. A. (1987). An analysis of multicultural education in the united states. Harvard Educational Review, 57(4), 421-444.

Torok, C. E., \& Aguilar, T. E. (2000). Changes in preservice teachers' knowledge and beliefs about language issues. Equity \& Excellence in Education, 33(2), 24-31.

Tran, M. T., Young, R. L., \& Di Lella, J. D. (1994). Multicultural education courses and the student teacher: Eliminating stereotypical attitudes in our ethnically diverse classroom. Journal of Teacher Education, 45(3), 183-189. (pp. 176-195). New York: Teachers College Press. 